\title{
Vitamin D Status in Different Categories of Glucose Intolerance in Bangladeshi Adults
}

\author{
Mohammad Firoj Hossain 1, *, Mohammad Shahed-Morshed ${ }^{2}$, Mohammed Fariduddin ${ }^{3}$, \\ Tahniyah $\mathrm{Haq}^{3}$, Shahjada Selim ${ }^{3}$, Muhammad Abul Hasanat ${ }^{3}$, Mohammad Habibul Ghani ${ }^{4}$, \\ Anil Yadav ${ }^{5}$, Ibrahim Faisal ${ }^{6}$, Anil Kumar Shah ${ }^{7}$ \\ ${ }^{1}$ Department of Endocrinology, Mugda Medical College, Dhaka, Bangladesh \\ ${ }^{2}$ Emergency Department, Kurmitola General Hospital, Dhaka, Bangladesh \\ ${ }^{3}$ Department of Endocrinology, Bangabandhu Sheikh Mujib Medical University, Dhaka, Bangladesh \\ ${ }^{4}$ Department of Medicine, Jinjira 20 Bed Hospital, Keraniganj, Dhaka, Bangladesh \\ ${ }^{5}$ Department of Internal Medicine (Endocrinology Division), Birat Medical College Teaching Hospital, Biratnagar, Nepal \\ ${ }^{6}$ Deprtment of Medicine, Indira Gandhi Memorial Hospital, Kanbaa Aisa Rani Higun, Male, Republic of Maldives \\ ${ }^{7}$ Department of Medicine (Endocrinology Unit), Chitwan Medical College, Chitwan, Nepal
}

\section{Email address:}

dr.firojhossain@gmail.com (M. F. Hossain)

${ }^{*}$ Corresponding author

\section{To cite this article:}

Mohammad Firoj Hossain, Mohammad Shahed-Morshed, Mohammed Fariduddin, Tahniyah Haq, Shahjada Selim, Muhammad Abul Hasanat, Mohammad Habibul Ghani, Anil Yadav, Ibrahim Faisal, Anil Kumar Shah. Vitamin D Status in Different Categories of Glucose Intolerance in Bangladeshi Adults. International Journal of Diabetes and Endocrinology. Vol. 6, No. 1, 2021, pp. 24-30.

doi: $10.11648 /$ j.ijde.20210601.15

Received: January 5, 2021; Accepted: January 18, 2021; Published: January 28, 2021

\begin{abstract}
Background and aims: Although vitamin D deficiency (VDD) is inversely associated with glucose intolerance, very limited data are available in Bangladesh. Thus, the study aimed to determine vitamin D status of Bangladeshi adults based on the glucose intolerance status. Materials \& Methods: This cross-sectional study was carried out among 70 newly detected DM, age-group \& sex-matched 76 newly detected pre-diabetes and 74 healthy control with normal glucose tolerance (NGT) based on American Diabetes Association, 2018 criteria. Participants were included consecutively from the Department of Endocrinology, Bangabandhu Sheikh Mujib Medical University (BSMMU) over a period of 1 year by convenient sampling to see serum $25(\mathrm{OH}) \mathrm{D}$ which was measured by high performance liquid chromatography (HPLC) method. Results: Vitamin D levels decreased with increasing degrees of glucose intolerance [NGT: 16.82 \pm 6.57 ; prediabetes: 15.54 \pm 8.58 ; T2DM: $11.01 \pm 6.03 \mathrm{ng} / \mathrm{ml}, \mathrm{p}<0.001]$ but significantly lower in T2DM than other two groups [T2DM vs. prediabetes, $\mathrm{p}=0.001$; T2DM vs. control, $\mathrm{p}<0.001$; prediabetes vs. control, $\mathrm{p}=\mathrm{NS}]$. The highest frequency of vitamin $\mathrm{D}$ deficiency was among individuals with T2DM $(64.3 \%)$ followed by NGT $(29.7 \%)$ and prediabetes $(28.9 \%)$ [p $<0.001]$. Only $\mathrm{HbA}_{1} \mathrm{c}$ had predictive association with vitamin D deficiency [OR $\left.(95 \% \mathrm{CI})=2.061(1.178,3.608), \mathrm{p}=0.011\right]$. Only DM but not pre-diabetes had predictive association with vitamin D deficiency compared with NGT [DM: OR $(95 \% \mathrm{CI})=4.255(2.117$, 8.552), $\mathrm{p}<0.001$; prediabetes: OR $(95 \% \mathrm{CI})=0.963(0.477,1.946), \mathrm{p}=0.916]$. Conclusion: Vitamin $\mathrm{D}$ level was lower and frequency of vitamin D deficiency was higher in patients with DM. Only $\mathrm{HbA}_{1} \mathrm{c}$ and DM had predictive association with vitamin D deficiency.
\end{abstract}

Keywords: Vitamin D, Type 2 Diabetes, Prediabetes, Bangladeshi Adults

\section{Introduction}

Vitamin D has gain a lot of interest in recent years due to the discoveries of several extra-skeletal roles including 
glucose homeostasis. Many physiological functions are thought to be affected by vitamin D deficiency (VDD) [1]. An association of VDD with different non-communicable diseases also supports its importance in health and disease [2-4]. Similarly VDD adversely affects the function of $\beta$ cells of pancreas and insulin resistance by diverse mechanisms [5]. So a negative association between glycemic status with vitamin D status was described in many Western population [6, 7]. Bangladesh is now facing a huge burden of diabetes mellitus (DM) and prediabetes with a population prevalence of $10 \%$ and $23 \%$ respectively [8], with their associated complications and cost. So, primary and secondary prevention of DM is one of the top priorities in the control of non-communicable diseases. Targeting modifiable risk factors like VDD may be an appealing option. Correction of VDD has been found to be associated with DM prevention and glycemic control in several studies. However, data are conflicting and may depend on genetic factors. Vitamin D across the continuum of glucose intolerance has not been previously studied in Bangladeshi population. Besides, hypovitaminosis D is a pandemic condition in many regions of the world despite having a plentiful sunshine including Bangladesh. Previous studies from Bangladesh found high prevalence of VDD in different population groups including children and reproductive age females $(\sim 80 \%)$ [9]. So, identifying VDD especially in persons with glucose intolerance may provide an opportunity to reduce the health hazards. Hence, this study is aimed to compare vitamin D in different categories of glucose intolerance, and determine its association with glycemic variables and status.

\section{Materials and Methods}

\subsection{Study Design and Population}

This observational cross-sectional study was carried out in the Department of Endocrinology, BSMMU over a period of one year between March 2018 to February 2019. In this study 70 newly detected DM, age-group \& sex-matched 76 newly detected prediabetes and 74 healthy control with normal glucose tolerance (NGT) based on American Diabetes Association, 2018 criteria were included by convenient sampling.

Before the commencement the study protocol obtained ethical clearance from the Institutional Review Board of Bangabandhu Sheikh Mujib Medical University (BSMMU). Informed written consent was taken from each participant.

\subsection{Inclusion and Exclusion Criteria}

The study included adults ( $\geq 18$ years) attending at Department of Endocrinology, BSMUU. Participant's who were currently taking or had received vitamin D or calcium with in the last 120 days of sample collection; or those with known liver disease, renal disease, severe heart failure, autoimmune disease, metabolic bone disorder, malabsorption syndrome, active malignancy, concurrent critical illness; or pregnancy and lactation were excluded from the study.

\subsection{Data Collection}

Patient's clinical information was collected in a pretested record form. Participants were asked about their sociodemographic statuses, personal information and factors affecting vitamin D level by face-to-face interview. Height, weight, waist circumference and blood pressure of each participant were measured as per standard procedures.

\subsection{Biochemical Analysis}

About $10 \mathrm{ml}$ of venous blood was collected from each participant after an overnight fasting of 8-12 hours. Two (2) milliliters of blood was separated in a tube containing fluoride oxalate and $8 \mathrm{ml}$ of blood was taken in to a gel separator tube covered by aluminum foil. After 10-15 minutes of collection, blood sample tubes were placed in a centrifuge and spun at $3000 \mathrm{rpm}$ for 10 minutes in a dark room to obtain the serum. Blood glucose was measured immediately and serum was stored appropriately at $-20^{\circ} \mathrm{C}$ and was analyzed for serum $\mathrm{HbA}_{1} \mathrm{c}$ and 25-hydroxyvitamin $\mathrm{D}\{25(\mathrm{OH}) \mathrm{D}\}$ within a week of sample collection. Two hours after a 75 gm oral glucose, a second sample of about $3 \mathrm{ml}$ venous blood was taken and sent for 2 hours after $75 \mathrm{gm}$ oral glucose tolerance test (2h-OGTT) glucose measurement. Blood glucose was measured by glucose oxidase method and $\mathrm{HbA}_{1} \mathrm{c}$ by turbid metric inhibition immunoassay. Vitamin D was measured by high performance liquid chromatography (HPLC) method with a coefficient of variability of $2.6 \%-4.9 \%$ and analytical sensitivity of $2-100$ $\mathrm{ng} / \mathrm{ml}$.

\subsection{Operational Definitions}

Prediabetes (impaired fasting glucose or impaired glucose tolerance) or T2DM were considered as glucose intolerance. According to ADA, 2018 criteria, prediabetes was diagnosed any one from below: fasting blood glucose, $\mathrm{FBG}=5.6-6.9 \mathrm{mmol} / \mathrm{L}$ (IFG), 2 hours after $75 \mathrm{gm}$ OGTT=7.8-11 mmol/L (IGT) or $\mathrm{HbA}_{1} \mathrm{c}=5.7-6.4 \%$ ? and T2DM was defined as patient fulfilling any criteria of FBG $\geq 7 \mathrm{mmol} / \mathrm{L}, 2$ hours plasma glucose after 75 gm OGTT $\geq 11.1 \mathrm{mmol} / \mathrm{L}, \mathrm{HbA}_{1} \mathrm{c} \geq 6.5 \%$ or in a patient with classical symptoms of hyperglycemia or hyperglycemic crisis, a random plasma glucose $\geq 11.1 \mathrm{mmol} / \mathrm{L}$ for the first time at presentation without any history of ketoacidosis and clinical features suggesting other types of DM [10]. Vitamin D status was categorized by Institute of Medicine (IOM), 2011 criteria in to vitamin D sufficiency $(\geq 20 \mathrm{ng} / \mathrm{ml})$, insufficiency (12-19.99 ng/ml) and deficiency $(<12 \mathrm{ng} / \mathrm{ml})$ [11].

\subsection{Statistical Analysis}

All data were analyzed by SPSS Statistics software version 22.0. Qualitative values were expressed by frequency (percentages, \%) and quantitative values (here, all were normally distributed) by mean \pm standard deviation (SD). 
Quantitative values across the groups were compared by one way analysis of variance (ANOVA) test with post hoc analysis by Tukey test. Qualitative values were analyzed by Pearson's Chi-square test. Correlation of vitamin D with various glycemic values were done by Pearson's correlation test. Linear regression analysis was done to see the predictive association of vitamin D level as dependent and glycemic values as independent variables. Binary and multinomial logistic regression analysis was done to see the predictive association with VDD with different glycemic values and status respectively.

\section{Results}

A total of 220 participants including 70 patients with T2DM, 76 with prediabetes and 74 healthy control with NGT were studied in this study. The BMI, waist circumference and diastolic blood pressure of people with prediabetes were significantly higher than the other two groups. Other parameters such as age and systolic blood pressure were not significantly different across the spectrum of glucose intolerance (Table 1).

Table 1. Characteristics of the study population $(n=220)$.

\begin{tabular}{|c|c|c|c|c|c|}
\hline Variables & Diabetes mellitus (DM) & Prediabetes & $\begin{array}{l}\text { Normal glucose } \\
\text { tolerance (NGT) }\end{array}$ & $\mathbf{p}$ & Significant differences between groups \\
\hline \multirow[t]{2}{*}{ Number } & 70 & 76 & 74 & & \\
\hline & & Mean \pm SD & & & \\
\hline Age, (years) & $42.27 \pm 10.65$ & $38.75 \pm 10.70$ & $40.81 \pm 10.82$ & 0.139 & - \\
\hline BMI $\left(\mathrm{kg} / \mathrm{m}^{2}\right)$ & $26.20 \pm 4.19$ & $28.92 \pm 4.13$ & $25.88 \pm 4.59$ & $<0.001$ & Prediabetes: vs. DM, $\mathrm{p}=0.001$; vs. NGT, $\mathrm{p}<0.001$ \\
\hline \multicolumn{6}{|l|}{$\mathrm{WC}(\mathrm{cm})$} \\
\hline Male & $87.77 \pm 6.66$ & $96.05 \pm 14.48$ & $87.94 \pm 7.79$ & 0.056 & - \\
\hline Female & $89.58 \pm 11.32$ & $99.69 \pm 9.05$ & $85.03 \pm 12.76$ & $<0.001$ & Prediabetes: vs. DM, $\mathrm{p}<0.001$; vs. NGT, $\mathrm{p}<0.001$ \\
\hline SBP (mmHg) & $123.0 \pm 18.60$ & $119.30 \pm 16.0$ & $119.87 \pm 18.19$ & 0.40 & - \\
\hline DBP (mmHg) & $78.0 \pm 11.24$ & $81.0 \pm 10.66$ & $76.15 \pm 10.84$ & 0.024 & Prediabetes vs. NGT, $\mathrm{p}=0.019$ \\
\hline
\end{tabular}

One way ANOVA with post hoc Tukey test was done

As shown in Table 2, most of the risk factors associated with VDD were similar among the three groups of glucose intolerance. However, the people with DM smoked more frequently than the other two groups. Similar to Table 1, adults with prediabetes were more obese than DM and NGT groups.

Table 2. Risk factors of vitamin D deficiency in the study population $(n=220)$.

\begin{tabular}{|c|c|c|c|c|}
\hline Risk factors of vitamin D deficiency & Diabetes mellitus & Prediabetes & Normal glucose tolerance & $\mathbf{p}$ \\
\hline Number & 70 & 76 & 74 & \\
\hline \multicolumn{5}{|c|}{ Frequency $(\%)$} \\
\hline Age $\geq 60$ years & $5(7.1)$ & $5(6.6)$ & $3(4.1)$ & 0.771 \\
\hline Female gender & $57(81.4)$ & $61(80.3)$ & $58(78.4)$ & 0.891 \\
\hline Urban resident* & $47(67.1)$ & $60(78.9)$ & $62(83.8)$ & 0.054 \\
\hline Not completed primary education & $14(20.0)$ & $12(15.8)$ & $7(9.5)$ & 0.213 \\
\hline Occupation: unemployed, retired¥ & $7(10.0)$ & $7(9.2)$ & $6(8.1)$ & 0.957 \\
\hline Smoker (current/past) & $25(35.7)$ & $12(15.8)$ & $9(12.2)$ & 0.001 \\
\hline Low physical activity $\Psi$ & $38(54.3)$ & $42(55.3)$ & $41(55.4)$ & 1.00 \\
\hline Obese $\left(B M I \geq 27.5 \mathrm{~kg} / \mathrm{m}^{2}\right) \tilde{\imath}$ & $25(35.7)$ & $45(59.2)$ & $18(24.3)$ & $<0.001$ \\
\hline Centrally obese (WC: $M \geq 90 \mathrm{~cm}, \mathrm{~F} \geq 80 \mathrm{~cm})$ & $56(80.0)$ & $71(93.4)$ & $48(64.9)$ & $<0.001$ \\
\hline Hypertensive ( $\mathrm{BP} \geq 140 / 90 \mathrm{~mm}-\mathrm{Hg}$ or on antihypertensive drugs) & $21(30.0)$ & $17(22.4)$ & $17(23.0)$ & 0.530 \\
\hline Inadequate sunlight exposure timet & $37(52.9)$ & $43(56.6)$ & $51(68.9)$ & 0.121 \\
\hline Use sunscreen (sun protecting factor $\geq 8$ ) & $5(7.1)$ & $5(6.6)$ & $9(12.2)$ & 0.435 \\
\hline Consuming less vitamin D containing food£ & $28(40.0)$ & $22(28.9)$ & $19(25.7)$ & 0.153 \\
\hline
\end{tabular}

Within parentheses are percentages over column total of respective variable; Pearson's Chi-square test was done

* According to Bangladesh national conservation strategy, 2013

T According to monthly household income

I According to Mayo clinic smoking status category

$¥$ According to registrar general occupational classification

$\Psi$ According to international physical activity questionnaire- short form

+ Atleast 10 minutes a day in between 11 am to 2 pm, at least 3 days a week

$£$ At least 1 serving of egg yolk or large fish per day, at least 4 days a week

The mean value of serum 25(OH)D was significantly lower in patients with DM than both prediabetes and NGT (Figure 1). 


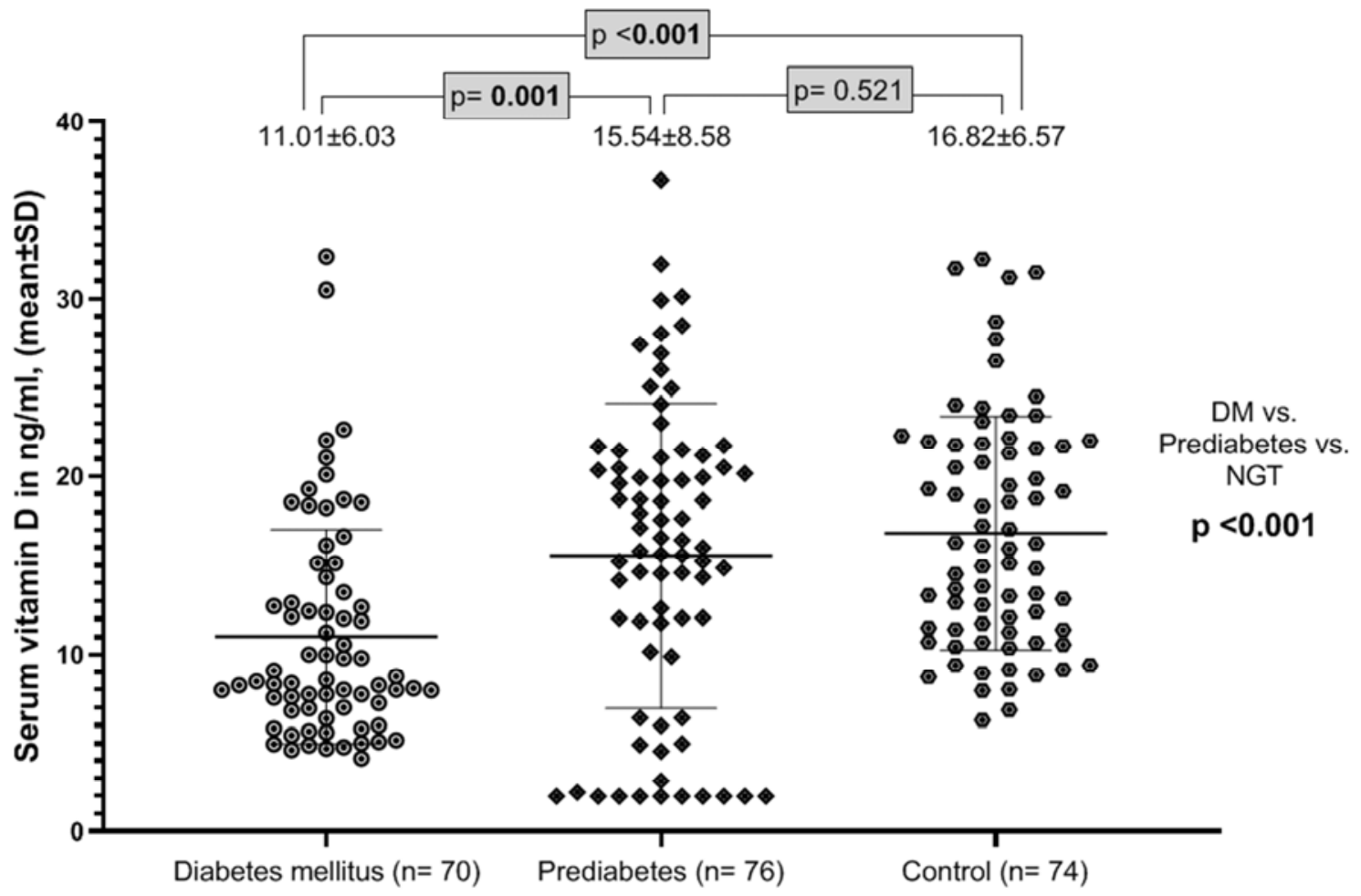

Glycemic status of the study population $(\mathrm{N}=\mathbf{2 2 0})$

Figure 1. Serum vitamin D level in different categories of glucose intolerance $(N=220)$.

Similarly, there was an association between vitamin D and glycaemic status, where patients with DM had the greatest number of cases with VDD (Figure 2).

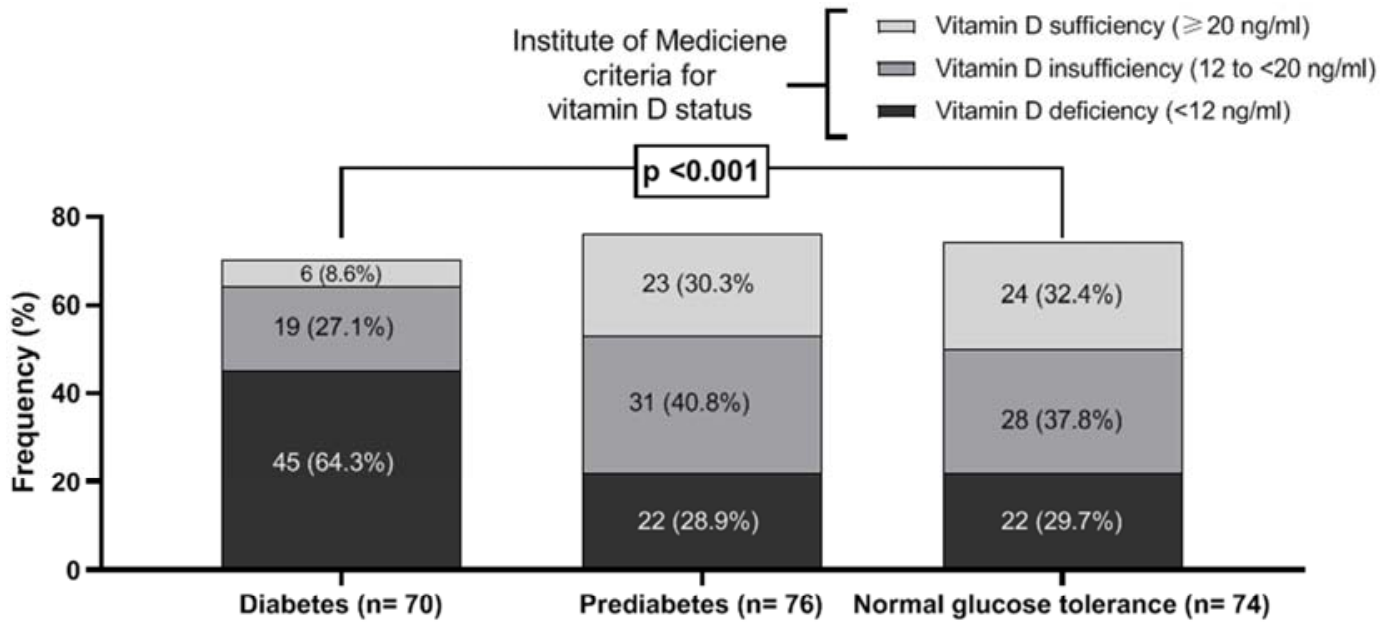

Glycemic status of the study population $(\mathrm{N}=220)$

Figure 2. Vitamin D status in different categories of glucose intolerance $(n=220)$.

Serum vitamin $\mathrm{D}$ had significant negative correlation with all the glycemic values (FBG, 2H-OGTT glucose and $\mathrm{HbA}_{1} \mathrm{c}$ ) in the study population. Linear regression analysis also showed significant negative association of them individually with serum vitamin D (Figure 3). After adjustment for factors affecting VDD (age, body mass index, waist circumference, systolic and diastolic blood pressure), only FBG andHbA $\mathrm{c}$ had predictive association with VDD status [B $(95 \% \mathrm{CI}), \beta$ : $\mathrm{FBG}=-0.346(-0.639,-0.052),-0.155, \mathrm{p}=0.021 ; \mathrm{HbA}_{1} \mathrm{c}=-2.140$ $(-3.199,-1.080),-0.616, \mathrm{p}<0.001]$. 


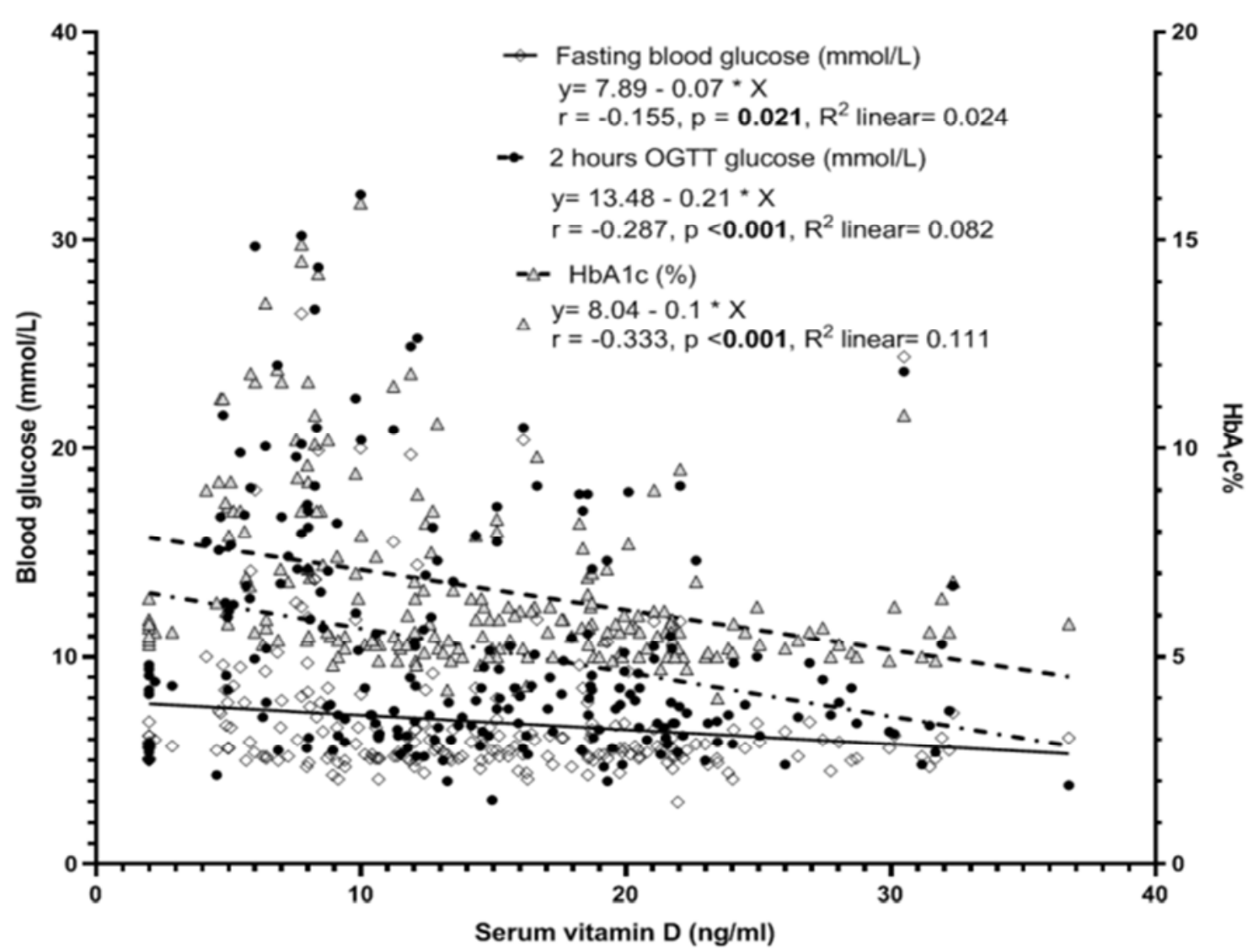

Pearson's correlation test was done, $\mathrm{r}=$ correlation coefficient

Figure 3. Correlation of serum vitamin D with different glycemic values in the study population.

Binary logistic regression analysis showed that only $\mathrm{HbA}_{1} \mathrm{c}$ had predictive association with VDD $(<20 \mathrm{ng} / \mathrm{ml})$ after adjustment for other factors affecting vitamin D level. 1\% increase of $\mathrm{HbA}_{1} \mathrm{c}$ was associated with 2.061 times higher odds of being vitamin $\mathrm{D}$ deficient (Table 3).

Table 3. Predictive association of vitamin D deficiency (dependent factor) with different glycemic values.

\begin{tabular}{lll}
\hline Covariates & B & OR* (95\%CI) \\
\hline Fasting blood glucose & -0.187 & $0.830(0.645,1.067)$ \\
Glucose 2 hours after oral glucose tolerance test & .052 & $1.053(0.894,1.240)$ \\
$\mathrm{HbA}_{1} \mathrm{c}$ & 0.723 & $2.061(1.178,3.608)$ \\
Constant & -3.686 & 0.535 \\
\hline
\end{tabular}

Binary logistic regression analysis was done

$\mathrm{B}=$ regression coefficient, $\mathrm{OR}=$ odds ratio, $\mathrm{CI}=$ confidence interval

*Adjusted for age, sex, residence, occupation, educational, socioeconomic, smoking, obesity, central obesity, hypertension, sunlight exposure time \& body surface area, sunscreen use and vitamin D containing food intake status.

As shown in Table 4, only DM had predictive association with VDD in comparison to NGT in the study population but prediabetes had no significant association. Diabetes had
4.255 times increased risk of VDD in comparison to NGT after adjustment for other factors affecting vitamin D level.

Table 4. Predictive association of vitamin D deficiency (dependent factor) with different glycemic status.

\begin{tabular}{|c|c|c|c|}
\hline Independent factors & B & Odds ratio* (95\% confidence interval) & $\mathbf{P}$ \\
\hline Normal glucose tolerance & 1 (refer & & \\
\hline Prediabetes & -0.038 & $0.963(0.477,1.946)$ & 0.916 \\
\hline Diabetes & 1.448 & $4.255(2.117,8.552)$ & $<0.001$ \\
\hline Intercept & -0.860 & - & 0.001 \\
\hline
\end{tabular}

Multinomial logistic regression analysis was done; $\mathrm{B}=$ regression coefficient

*Adjusted for age, sex, BMI, systolic and diastolic blood pressure and smoking status 


\section{Discussion}

This study showed that vitamin D level was lower and VDD status was higher significantly in patients with DM than prediabetes and NGT. FBG and $\mathrm{HbA}_{1} \mathrm{c}$ had significant linear association with serum vitamin $\mathrm{D}$ but only $\mathrm{HbA}_{1} \mathrm{c}$ had predictive association with VDD. On the other hand, compared with NGT only DM but not prediabetes had predictive association with VDD. In the present study, we observed that about $64 \%$ of T2DM individuals had VDD. Additionally, a significantly higher proportion of individuals with T2DM had VDD compared those with prediabetes and NGT. Similar observations have been reported in T2DM patients from the area of South India [12], Athens \& Pireaus [13] and Saudi Arabia [14]. While study conducted by Modi et al [15] reported a higher prevalence of VDD compared to our study ( $84 \%$ in T2DM, $77 \%$ in prediabetes, $87 \%$ in NGT), using the cut-off for VDD by serum $25(\mathrm{OH}) \mathrm{D}<30 \mathrm{ng} / \mathrm{dl}$.

Many other study also showed higher prevalence of VDD in prediabetes than NGT [16, 17] compared to our study, all using the same cut-off for VDD (serum $25(\mathrm{OH}) \mathrm{D}<20 \mathrm{ng} / \mathrm{dl}$ ). Another finding in our study was more vitamin D insufficiency $(12-20 \mathrm{ng} / \mathrm{dl})$ in prediabetes compared to T2DM and NGT. This all might be explained by, use of different cut-off value $(<12 \mathrm{ng} / \mathrm{ml})$ to define VDD, different method of vitamin D estimation and different sample size in our study.

We found a significantly lower vitamin D level in patients with DM than the NGT, but not in prediabetes. So the deleterious effects of vitamin $\mathrm{D}$ may be visible at a lower level to affect $\beta$-cell function and insulin resistance. A Korean study also supported this finding [18]. On the contrary, others found lower serum vitamin D concentration and higher percentages of VDD in prediabetes than diabetes [19], and higher levels of $25(\mathrm{OH}) \mathrm{D}$ in the glycemic intolerance group than the control population [15]. These population-based study findings are inconsistent, indicating that the association between vitamin D and glucose tolerance may be varying in different ethnic groups; therefore, a prospective study about vitamin D and its inverse association with diabetes among Bangladeshi individuals should be performed as well.

Lower serum $25(\mathrm{OH}) \mathrm{D}$ levels were positively associated with prediabetes in the third National Health and Nutrition Examination Survey conducted in US population [20]. In our study we did not found the similar association of VDD with prediabetes. VDD may also be a risk factor for insulin resistance [21]. However, associations of vitamin D with insulin resistance were also inconsistent [22-24].

FBG and $\mathrm{HbA}_{1} \mathrm{c}$ had significant linear association with serum vitamin $\mathrm{D}$ but only $\mathrm{HbA}_{1} \mathrm{c}$ had predictive association with VDD. The difference between the two glycemic measures is that $\mathrm{HbA}_{1} \mathrm{c}$ reflects the average level of blood glucose over the past 2-3 months while FBG represents a single measurement of blood glucose concentration following over night fasting. $\mathrm{HbA}_{1} \mathrm{c}$ is relatively more stable than FBG on repeated measurements [25]. On the other hand, compared with NGT only DM but not prediabetes had predictive association with VDD. This may be possible due to the combined role of several factors affecting vitamin D rather than the glycemic values only.

The measurement of serum vitamin D by HPLC rather than immuno-assay based method was the main strength of our study. However the sample size was relatively small. Besides we could not measure serum calcium, phosphate and parathyroid hormone of our patients that might provide further information about the critical association of VDD with different categories of glycemic intolerance.

\section{Conclusion}

VDD was a common finding in Bangladeshi adults irrespective of glycemic status. However, only DM was significantly associated with vitamin $\mathrm{D}$ status. $\mathrm{HbA}_{1} \mathrm{c}$ and DM had better predictive associations with VDD. These study findings will guide us to look forward about the role of vitamin D supplementation in glycemic control especially in people with DM.

\section{Conflict of Interest}

The authors declare that they have no conflict of interest concerning this article.

\section{Financial Disclosure}

We obtained a grant from Beximco Pharmaceuticals Mfg. Ltd of Bangladesh for measurement of vitamin D.

\section{Acknowledgements}

We thank the Institutional Review Board as well as Department of Endocrinology of BSMMU for moral support. Technical support by the Microbiology and Biochemistry Department of BSMMU and Centre for Advanced Research in Sciences, Dhaka University are also duly acknowledged.

\section{References}

[1] Holick MF. Vitamin D: a d-lightful solution for health. J Investig Med. 2011; 59 (6): 872-80. doi: 10.2310/JIM.0b013e318214ea2d.

[2] Vimaleswaran KS, Cavadino A, Berry DJ, et al. Association of vitamin D status with arterial blood pressure and hypertension risk: a mendelian randomisation study. Lancet Diabetes Endocrinol. 2014; 2 (9): 719-29. doi: 10.1016/S2213-8587(14)70113-5.

[3] Scragg R, Sowers M, Bell C. Serum 25-hydroxyvitamin D, diabetes, and ethnicity in the Third National Health and Nutrition Examination Survey. Diabetes Care. 2004; 27 (12): 2813-8. doi: 10.2337/diacare.27.12.2813.

[4] Pludowski P, Holick MF, Pilz S, et al. Vitamin D effects on musculoskeletal health, immunity, autoimmunity, cardiovascular disease, cancer, fertility, pregnancy, dementia and mortality-a review of recent evidence. Autoimmun Rev. 2013; 12 (10): 976-89. doi: 10.1016/j.autrev.2013.02.004. 
[5] Dhas Y, MishraN, Banerjee J. Vitamin D deficiency and oxidative stress in type 2 diabetic population of India. Cardiovasc Hematol Agents Med Chem. 2017; 14 (2): 82-9. doi: $10.2174 / 1871525714666160426150233$.

[6] Scragg R, Holdaway I, Singh V, et al. Serum 25hydroxyvitamin $\mathrm{D}_{3}$ levels decreased in impaired glucose tolerance and diabetes mellitus. Diabetes Res Clin Pract. 1995; 27 (3): 181-8. doi: 10.1016/0168-8227(95)01040-k.

[7] Hutchinson MS, Figenschau Y, Almås B, et al. Serum 25hydroxyvitamin $\mathrm{D}$ levels in subjects with reduced glucose tolerance and type 2 diabetes - the Tromsø OGTT-study. Int J Vitam Nutr Res. 2011; 81 (5): 317-27. doi: 10.1024/03009831/a000079.

[8] Akter S, Rahman MM, Abe SK, et al. Prevalence of diabetes and prediabetes and their risk factors among Bangladeshi adults: a nationwide survey. Bull World Health Organ. 2014; 92 (3): 204-13, 213A. doi: 10.2471/BLT.13.128371.

[9] Mica A. Vitamin D status among Bangladeshi women of Reproductive age. Master Theses 1911, Feb2014. Avaiable at: https://scholarworks.umass.edu/cgi/viewcontent.cgi?article=1 $369 \&$ context $=$ theses

[10] American Diabetes Association. Classification and diagnosis of diabetes: standards of medical care in diabetes. Diabetes care. 2018; 41 (1): S13-S27.https://doi.org/10.2337/dc18-S002

[11] Aloia JF. The 2011 report on dietary reference intake for vitamin D: where do we go from here? J Clin Endocrinol $\begin{array}{llll}\text { Metab. } & 2011 ; & 96 & \text { (10): }\end{array}$ https://doi.org/10.1210/jc.2011-0090.

[12] Jayashri R, Venkatesan U, Shanthirani CS, et al. Prevalence of vitamin $\mathrm{D}$ deficiency in urban south Indians with different grades of glucose tolerance. Br J Nutr. 2020; 124 (2): 209-16. doi: $10.1017 / \mathrm{S} 0007114520001129$.

[13] Kostoglou-Athanassiou I, Athanassiou P, Gkountouvas A, et al Vitamin D and glycemic control in diabetes mellitus type 2 . Ther Adv Endocrinol Metab. 2013; 4 (4): 122-8. doi: $10.1177 / 2042018813501189$.

[14] Darraj H, Badedi M, Poore KR, et al. Vitamin D deficiency and glycemic control among patients with type 2 diabetes mellitus in Jazan City, Saudi Arabia. Diabetes Metab Syndr Obes. 2019; 12: 853-862. doi: 10.2147/DMSO.S203700.

[15] Modi KD, Ahmed MI, Chandwani R, et al. Prevalence of vitamin $\mathrm{D}$ deficiency across the spectrum of glucose intolerance. J Diabetes Metab Disord. 2015; 14: 54. doi: 10.1186/s40200-015-0179-5.
[16] Srinath KM, Shashidhara KC, Rajeev-Reddy G, et al. Pattern of vitamin D status in prediabetic individuals: a case control study at tertiary hospital in South India. Int J Res Med Sci. 2016; 4 (4): 1010-5. doi: http://dx.doi.org/10.18203/23206012.ijrms20160706.

[17] Bhatt SP, Misra A, Gulati S, et al. Lower vitamin D levels are associated with higher blood glucose levels in Asian Indian women with pre-diabetes: a population-based cross-sectional study in North India. BMJ Open Diabetes Res Care. 2018; 6: e000501. doi: 10.1136/bmjdrc-2017-000501.

[18] Rhee SY, Hwang YC, Chung HY, et al. Vitamin D and diabetes in Koreans: analyses based on the Fourth Korea National Health and Nutrition Examination Survey (KNHANES), 2008-2009. Diabet Med. 2012; 29 (8): 1003-10. doi: $10.1111 /$ j.1464-5491.2012.03575.x.

[19] Guan C, Zhen D, Tang X, et al. The status of 25hydroxyvitamin D across the spectrum of glucose tolerance among middle-aged and elderly Chinese individuals. Clin Endocrinol (Oxf). 2014; $8 \quad 1 \quad$ (6): 834-40. doi: 10.1111/cen.12574.

[20] Shankar A, Sabanayagam C, Kalidindi S. Serum 25hydroxyvitamin D levels and prediabetes among subjects free of diabetes. Diabetes Care. 2011; 34 (5): 1114-9. doi: $10.2337 / \mathrm{dc} 10-1203$.

[21] Sahasrabuddhe AV, Pitale SU, Gupta M, et al. Study of vitamin D levels and its correlation with insulin resistance. Natl J Physiol Pharm Pharmacol. 2017; 7 (9): 963-7. doi: 10.5455/njppp.2017.7.0309424042017.

[22] Gulseth HL, Gjelstad IM, Tierney AC, et al. Serum vitamin D concentration does not predict insulin action or secretion in European subjects with the metabolic syndrome. Diabetes Care. 2010; 33 (4): 923-5. doi: 10.2337/dc09-1692.

[23] Chiu KC, Chu A, Go VL, et al. Hypovitaminosis D is associated with insulin resistance and beta cell dysfunction. Am J Clin Nutr. 2004; 79 (5): 820-5. doi: 10.1093/ajcn/79.5.820.

[24] Kayaniyil S, Vieth R, Retnakaran R, et al. Association of vitamin $\mathrm{D}$ with insulin resistance and beta-cell dysfunction in subjects at risk for type 2 diabetes. Diabetes Care. 2010; 33 (6): 1379-81. doi: 10.2337/dc09-2321.

[25] Sherwani SI, Khan HA, Ekhzaimy A, et al. Significance of $\mathrm{HbAlc}$ test in diagnosis and prognosis of diabetic patients. Biomark Insights. 2016; 11: 95-104. doi: 10.4137/BMI.S38440. 